\title{
UN PROBLEMA LÓGICO CON LA TESIS KRIPKE-PUTNAM
}

\author{
Pierre Baumann ${ }^{1}$
}

RESUMEN: Este trabajo arguye que la tesis Kripke-Putnam es ininteligible desde un punto de vista lógico formal, debido a que no es implementable ni en lógica de primer orden ni en lógica de segundo orden.

PAlABRAS-ClAVE: Kripke; Putnam; Términos de Clases Naturales; Designación Rígida.

ABSTRACT: This paper argues that the Kripke-Putnam thesis on natural kind terms is unintelligible from a logical point of view, since it cannot be implemented in either first-order logic or second-order logic.

KEYWORDS: Kripke; Putnam; Natural Kind Terms; Rigid Designation. 


\section{INTRODUCCIÓN}

Este trabajo arguye que la tesis Kripke-Putnam es ininteligible desde un punto de vista lógico formal, debido a que no es implementable ni en lógica de primer orden ni en lógica de segundo orden. La $\S 2$ repasa brevemente la tesis KripkePutnam. Las $\S \S 3-4$ exponen el problema lógico en cuestión. La $\S 5$, la conclusión, reúne algunas observaciones finales y responde a una posible objeción a las conclusiones halladas en las secciones precedentes. El enfoque de este trabajo es enteramente crítico; no se defiende ninguna doctrina positiva que sirva como alternativa a la tesis Kripke-Putnam. ${ }^{2}$

\section{LA TESIS KRIPKE-PUTNAM}

La tesis Kripke-Putnam (expuesta en [KRIPKE, 1995, pp. 105-160], [PUTNAM, 2005] y [PUTNAM, 1975]) afirma que los términos de clases naturales son designadores rígidos. Putnam resume la tesis como sigue:

Kripke llama a una expresión designador "rígido" (en una oración dada) si (en esa oración) tal expresión se refiere al mismo individuo en todo mundo posible en el que el designador designa [a ese individuo]. Si extendemos esta noción de rigidez a los nombres de sustancias, entonces podemos expresar la teoría de Kripke y la mía diciendo que el término "agua" es rígido. (PUTNAM, 2005, p. 161) 
Más adelante Putnam añade que:

Debe quedar claro...que la doctrina de Kripke de que las palabras de géneros naturales [como "agua"] son designadores rígidos y nuestra doctrina de que son indéxicos no son sino dos maneras de plantear la misma cuestión. (PUTNAM, 2005, p. 164)

Por "término de clase natural" (o "nombre de sustancia" o "palabra de género natural") se quiere decir un término del lenguaje ordinario que se utiliza para denotar entidades o fenómenos del mundo natural. Algunos ejemplos de términos de clases naturales son "agua", "oro", "tigre", "rojo", "calor", "áspero", "barítono" y "luz". El lenguaje ordinario posee una cantidad enorme de términos de clases naturales. La tesis Kripke-Putnam les atribuye una propiedad semántica especial: rigidez o designación rígida. Como se indica en la primera cita de Putnam dada arriba, el concepto de "designador rígido" proviene de la obra de Kripke, y se define como una expresión que designa el mismo objeto en todos los mundos posibles donde existe el objeto. (KRIPKE, 1995, p. 51) Un "mundo posible," según Kripke, es un constructo teórico donde se representa una situación contrafactual o real compatible con las leyes de la lógica. Por ejemplo, existe un mundo posible donde Mitt Romney es el actual presidente de los Estados Unidos, ya que dicha situación contrafactual es lógicamente coherente. No hay nada ilógico o contradictorio con tal situación; si las circunstancias hubiesen sido distintas, Romney habría ganado la elección de 2012 y no Obama. En cambio, la situación donde Roma es la capital de Italia, 
y, al mismo tiempo, Roma no es la capital de Italia, sí es contradictoria; por ende, la misma no puede corresponder a un mundo posible, aun si es posible verbalizar dicha situación incoherente.

Es importante destacar que, para Kripke, los mundos posibles son meramente una herramienta formal para analizar ciertas dimensiones del lenguaje natural, tales como la intensional y la modal-incluyendo, por ejemplo, las nociones de necesidad y posibilidad-; él rechaza que se conciban como planetas distantes o universos paralelos en un sentido físico. Para efectos de nuestra discusión, tomaremos por buenos estos conceptos kripkeanos de rigidez y mundos posibles, ya que son prerrequisitos indispensables para lo que sigue. Esto no significa, sin embargo, que dichos conceptos sean totalmente válidos; aquí permaneceremos agnósticos en cuanto a la legitimidad de éstos.

Volvamos ahora a los términos de clases naturales. Sintácticamente, los términos de clases naturales no pertenecen a una sola categoría; son de distintos tipos gramaticales. Pueden ser sustantivos, adjetivos, verbos, adverbios, frases preposicionales, etc. Por ejemplo, "agua" es un sustantivo pero "rojo" es adjetivo. Ahora bien, semánticamente, se supone que estos términos compongan una categoría propia. En particular, se supone que sean predicados rígidos, y la rigidez a su vez implica otras propiedades semánticas específicas, a saber, referencialidad y no-descriptividad. ${ }^{3}$ Está claro que si los términos de clases naturales son rígidos, como afirma explícitamente la tesis Kripke-Putnam, entonces son referenciales, puesto que la rigidez se define como la mismidad de la referencia a través 
de mundos posibles. Y si son referenciales, entonces son nodescriptivos, en el sentido de que la aportación semántica de un término referencial es su referente y no la información cualitativa y descriptiva asociada al término. En cuanto a la dimensión lógica de los términos clases naturales, estos se comportan como predicados monádicos o poliádicos normales. Específicamente, se esquematizan en lógica de primer orden mediante letras predicativas y se presume que representan propiedades o conjuntos de objetos en modelos especificados como de costumbre. En lógica de segundo orden-quizás la lógica más adecuada para estos términosse esquematizan mediante contantes predicativas, como cualquier otro término general representable en dicha lógica.

Filosóficamente, la tesis Kripke-Putnam ha tenido un impacto doble. En primer lugar, la tesis sostiene que la semántica referencialista defendida por Kripke, Putnam, y muchos otros autores puede extenderse a términos generales también (los cuales a primera vista no parecen exhibir una relación directa con individuos específicos). En particular, sugiere que estos términos tienen una semántica muy parecida a la de los nombres propios, las expresiones consideradas referenciales y rígidas por excelencia. Kripke a menudo recalca esta supuesta similitud entre los nombres propios y los términos de clases naturales:

De acuerdo con la posición que defiendo, entonces, los términos de clases naturales son mucho más parecidos a los nombres propios de lo que generalmente se supone. El antiguo término "nombre común" es por lo tanto 
muy apropiado para los predicados que señalan clases naturales, tales como "vaca" y tigre". Sin embargo, mis consideraciones se aplican también a algunos "términos masa" [mass terms] de clases naturales, tales como "oro", "agua" y otros similares. (Kripke, 1995, p. 124)

Asípues, paralelamenteal nombre propio "BarackObama", por ejemplo, el cual se supone designa el mismo hombre en todos los mundos posibles donde éste existe, el término de clase natural "agua" designa la misma sustancia, $\mathrm{H}_{2} \mathrm{O}$, en todos los mundos posibles donde existe dicha sustancia. Para efectos lógicos y semánticos, de acuerdo a la tesis KripkePutnam, lo importante es el referente del término, a saber, la sustancia que llamamos "agua"-el compuesto químico en sí-y no la información asociada con la palabra, como por ejemplo "líquido incoloro e insaboro que cae del cielo como lluvia y se usa para saciar la sed, limpiar, cocinar y bañarse, etc." Asimismo, la información cualitativa asociada al nombre "Barack Obama"-por ejemplo, "el cuadragésimo cuarto presidente de los EEUU, el ganador del Premio Nobel de la Paz de 2009, el líder demócrata que instauró la reforma médica llamada Obamacare, etc."-es irrelevante lógica y semánticamente; la aportación vericondicional (= semántica) del nombre es simplemente su referente, el individuo llamado Barack Obama.

En segundo lugar, la tesis Kripke-Putnam trae consigo ciertas consecuencias ontológicas. En particular, implica que existen propiedades naturales esenciales, dándole así un nuevo empuje al esencialismo en ontología. La tesis implica un esencialismo, porque presuntamente lo que denota rígidamente el término de clase natural es una propiedad 
específica e incambiante perteneciente a las entidades que integran la clase natural-en otras palabras, una esencia. Tanto Kripke como Putnam acogieron abiertamente dicha implicación esencialista (ambos se autodenominan "esencialistas"), y, en efecto, el esencialismo modal, o modalismo, propugnado por estos autores cobró un gran auge en la filosofía analítica de la segunda mitad del Siglo $\mathrm{XX}$. Son muchos los filósofos que han defendido esta posición metafísica en las últimas décadas.

Pese a su considerable popularidad, la tesis KripkePutnam no ha estado exenta de críticas. De hecho, a lo largo de los años éstas han sido numerosas y han venido tanto desde el punto de vista semántico como desde el punto de vista ontológico. Como se indicara arriba, la crítica presentada en este trabajo es de naturaleza lógica. Pasamos ahora a discutirla.

\section{LA TESIS KRIPKE-PUTNAM Y LA LÓGICA DE PRIMER ORDEN}

El problema es el siguiente; puede formularse como un dilema. La lógica de los términos de clases naturales ha de capturarse ya sea en lógica de primer orden o en lógica de segundo orden, o en ambas lógicas. Esto quiere decir, a su vez, que las condiciones de verdad de las oraciones que contienen estos términos deben poder explicitarse correctamente en una de las dos lógicas, o en ambas. Ahora bien, si asumimos que la lógica correcta para estos términos es la lógica de primer orden, entonces por razones técnicas que discutiremos a continuación, no podemos decir que éstos sean referenciales en el sentido requerido por la tesis 
Kripke-Putnam. Por ende no son rígidos, ya que rigidez presupone referencialidad. Por otro lado, si acudimos a la lógica de segundo orden, entonces tampoco podemos concluir que estos términos sean rígidos en un sentido filosóficamente interesante de la palabra; en este caso la noción de rigidez se trivializaría, como explicaremos abajo. La conclusión, por tanto, es que la tesis Kripke-Putnam es simplemente incoherente desde un punto de vista lógico.

En esta sección examinaremos el primer cuerno del dilema: los términos de clases naturales en lógica de primer orden. La próxima sección (la §3) está dedicada a la perspectiva de la lógica de segundo orden.

El problema que hay con la primera alternativa se resume como un sorites que llega a su conclusión a través de dos aplicaciones de modus tollendo tollens. ${ }^{4}$ Luego explicamos las premisas del argumento con más detalle.

\section{Primera premisa}

1. Todo término genuinamente referencial de la lógica de primer orden es inmune a cambios de alcance.

\section{Segunda premisa}

2. Sin embargo, los términos de clases naturales, simbolizados en lógica de primer orden, no son inmunes a cambios de alcance.

\section{Primera conclusión/Tercera premisa}

3. Por lo tanto no son genuinamente referenciales. (Por modus tollendo tollens, líneas 1 y 2.) 


\section{Cuarta premisa}

4. Todo término rígido es referencial. (Corolario inmediato de la tesis Kripke-Putnam.)

\section{Segunda conclusión}

5. Por lo tanto los términos de clases naturales no son rígidos. (Por modus tollendo tollens, líneas 3 y 4 .)

En la primera premisa, por "inmune a cambios de alcance" queremos decir que un término referencial de la lógica de primer orden puede moverse dentro o fuera del alcance de los cuantificadores que contenga una oración, sin afectar las condiciones de verdad y valor veritativo de ésta. Así pues, si el término estaba inicialmente dentro del alcance de un cuantificador, lo podemos sacar para afuera, conservando con todo los valores vericondicional y veritativo de la oración original. Y lo inverso también es cierto: Si primeramente estaba fuera del alcance del cuantificador, al colocarlo adentro no se afectan los valores mencionados de la oración. Y esto es así independientemente del número de cuantificadores que contenga la oración.

Esta primera premisa no debe resultar sorprendente o controversial, porque corresponde a un principio lógico básico conocido como "las reglas de pasaje". Las reglas de pasaje dicen precisamente que las proposiciones sobre individuos específicos, identificados mediante términos referenciales, por ejemplo por constantes individuales, pueden entrar o salir del alcance de un cuantificador sin alterar el valor veritativo de la oración o su sentido lógico. Por 
ejemplo, podemos probar fácilmente que la proposición $(\exists x)$ $(\mathrm{Fx} \& \mathrm{Ga})$ y la proposición $\mathrm{Ga} \&(\exists \mathrm{x}) \mathrm{Fx}$ son equivalentes. En este caso el término referencial $a$, una constante individual, pasa de estar dentro del alcance del cuantificador existencial, $(\exists \mathrm{x})$, a estar fuera de él. Como es bien sabido, este principio es válido para prácticamente todas las combinaciones posibles de constantes, cuantificadores, variables, funtores, letras predicativas y conectivas lógicas. La excepción son las oraciones que contienen el bicondicional, pero dicha excepción es poco importante, ya que el bicondicional es definible en términos de otras conectivas y se puede eliminar del lenguaje.

Lo que expresa la segunda premisa, entonces, es que los términos de clases naturales, representados en esta lógica, no obedecen las reglas de pasaje: el movimiento del término vis à vis los cuantificadores de la oración sí altera las condiciones de verdad y el valor veritativo de la misma. Esto tampoco debe resultar particularmente extraño, puesto que para efectos lógicos los términos de clases naturalesque, recordemos, son expresiones del lenguaje ordinario-se esquematizan como letras predicativas y las letras predicativas se comportan de manera distinta a las constantes individuales u otras expresiones referenciales. Estos términos no tienen un estatus especial en lógica y ciertamente no se simbolizan por medio de constantes individuales. En particular, contrario a las constantes individuales o los funtores saturados, las letras que representan dichos términos no son referenciales en un sentido fuerte sintáctico-semántico según el cual escapan a cualquier cambio de alcance. 
Ahora bien, se podría tal vez objetar que los términos de clases naturales son referenciales porque son extensionalestienen que serlo en lógica de primer orden. Esto es un error. Es cierto, por supuesto, que tanto la lógica de primer orden como la de segundo orden son extensionales. Lo que esto quiere decir es que el "significado" de una expresión perteneciente a uno de estos lenguajes es la extensión de la expresión; es simplemente la entidad denotada por la expresión. (O, más precisamente, es la entidad asignada a la expresión por la función interpretativa del modelo pretendido para el lenguaje.) En el caso de los términos de clases naturales, la extensión sería una propiedad o conjunto, como sucede con cualquier otro tipo de predicado representable en lógica de primer orden.

Si bien es cierto que a menudo en lógica los términos "extensional" y "referencial" se usan intercambiablemente, como si fueran sinónimos, no lo son en realidad. Hablando estrictamente, sí hay una distinción entre "extensional" y "referencial"; todas las expresiones de un lenguaje de primer o segundo orden son extensionales, pero sólo algunas son referenciales. O, puesto de otro modo, todo término referencial es extensional, pero no todo término extensional es referencial. Las expresiones genuinamente referenciales son aquellas que denotan un solo individuo. (En lógica de primer orden, éstas son las constantes individuales o los funtores que tienen una constante como argumento.) Por tanto, desde un punto de vista lógico, los términos de clases naturales son extensionales, pero no son referenciales. (Cabe destacar que el propio Putnam enfatiza esta sutil distinción en [PUTNAM, 2005].) 
Volviendo al argumento, la verdad de la segunda premisa se prueba fácilmente mediante ejemplos. Consideremos la siguiente oración:

(1) Una mujer le dio una zanahoria a cada conejo.

La oración contiene tres términos de clases naturales, "mujer", "zanahoria" y "conejo", y una posible esquematización sería la siguiente:

(1a) $(\exists x)(\exists y)[(M x \& Z y) \&(\forall z)(C z \supset D x y z)]$

[Donde $M$ representa "mujer", $Z$ representa "zanahoria", $C$ representa "conejo" y $D$ representa "dar" (o "darle").]

En la esquematización podemos apreciar que "conejo" está dentro del alcance de todos los cuantificadores. ${ }^{5}$ En cuanto a las condiciones de verdad, la oración (1) es verdadera si existe una mujer que le dio por lo menos una zanahoria a todos los conejos en cuestión.

Ahora bien, no es posible extraer el término "conejo", o si se prefiere, el sintagma nominal "cada conejo", y otorgarle alcance primario frente a los demás cuantificadores, sin que esto altere las condiciones de verdad de la oración (1). Si lo hacemos obtendríamos el siguiente esquema:

(1b) $(\forall z)[C z \supset(\exists x)(\exists y)\{(M x \& Z y) \&(D x y z)\}]$

Pero (1b) no es equivalente a (1a). En particular, (1a) implica lógicamente (1b), pero no viceversa. 
Lo mismo ocurre con oraciones donde es el universal el que tiene alcance primario relativo al existencial. Veamos el siguiente ejemplo:

(2) Todos los gatos odian a algún perro.

Esta oración contiene dos términos de clases naturales, "gato" y "perro", y una posible esquematización sería la siguiente:

(2a) $(\forall x)[G x \supset(\exists y)(P y \& O x y)]$

[Donde $G$ representa "gato", $P$ representa "perro" y $O$ representa "odiar".]

Si extraemos el sintagma nominal "algún perro" y lo colocamos al principio de la oración, dándole así alcance primario frente a "todos los gatos", entonces obtenemos el esquema (2b), el cual no es lógicamente equivalente a (2a):

(2b) $(\exists x)[\operatorname{Px} \&(\forall y)(G y \supset O y x)]$

En efecto, (2b) implica (2a), pero no al revés. Como hay implicación en una sola dirección, no puede ser que los dos esquemas tengan los mismos valores vericondicionales.

Fíjese que lo mismo no sucede cuando tenemos esquemas que contienen términos referenciales genuinos; en este caso sí se conserva el valor vericondicional de la oración tras una permutación de alcance. Ya se ha mencionado un ejemplo genérico, que sirve para ilustrar las reglas de pasaje, pero lo mismo se puede apreciar en esta otra oración levemente más compleja: 
(3) Aristóteles es un filósofo respetado por todos.

La oración (3) se puede esquematizar como (3a) o como (3b), pero ambos esquemas son equivalentes, lo que comprueba que tienen los mismos valores vericondicional y veritativo.

(3a) $\mathrm{Fa} \&(\forall \mathrm{x}) \mathrm{Rxa}$

(3b) $(\forall x)(F a \& R x a)$

[Donde $F$ esquematiza "es un filósofo", $R$ esquematiza "es respetado por" y a denota a Aristóteles.]

Habiendo justificado de esta manera la segunda premisa, la única que quizás podría resultar un poco oscura a primera vista, la conclusión del argumento se torna ineludible. (Debe estar claro que la primera premisa es trivial, la cuarta es un corolario inmediato de la tesis Kripke-Putnam-como se ha dicho anteriormente, rigidez implica referencialidad-y los demás pasos se siguen por razonamiento lógico elemental.) Por consiguiente, la tesis Kripke-Putnam no puede ser correcta desde el punto de vista de la lógica de primer orden.

\section{LA TESIS KRIPKE-PUTNAM Y LA LÓGICA DE SEGUNDO ORDEN}

Considerémosla entonces desde la óptica de la lógica de segundo orden. Éste es el segundo cuerno del dilema. Al igual que con el primer cuerno, primero resumimos el argumento, presentándolo de forma explícita, y luego lo explicamos más detalladamente. 


\section{Primera premisa}

1. Si los términos de clases naturales son rígidos en lógica de segundo orden, entonces también lo son otros predicados.

\section{Segunda premisa}

2. Si estos otros predicados son rígidos, entonces se trivializa la noción de rigidez.

\section{Conclusión}

3. Por lo tanto, si los términos de clases naturales son rígidos en lógica de segundo orden, se trivializa la noción de rigidez (y por ende deja de ser filosóficamente interesante la tesis Kripke-Putnam). [El argumento es lógicamente válido por ejemplificar el patrón de razonamiento conocido como "silogismo hipotético".]

Nuevamente tenemos aquí un argumento sencillo con una conclusión derivable mediante razonamiento lógico básico. Parecería, además, que en este caso las premisas son bastante evidentes en sí mismas. La única premisa que quizás requiere un poco de explicación y prueba es la primera; la segunda se capta fácilmente, porque está compuesta por palabras que se usan de acuerdo a su sentido normal de diccionario o por términos técnicos definidos previamente. Por supuesto, una vez se haya establecido la primera premisa, el resto del argumento fluye a toda velocidad hasta la conclusión. 
Procedemos entonces a explicar y justificar la primera premisa. La premisa es de tipo condicional; por ende es verdadera cuando su antecedente es falso o el consecuente es verdadero. Sin embargo, aquí antecedente y consecuente están conceptualmente ligados. (De hecho, el consecuente es elíptico.) Por esta razón, para determinar si éstos son verdaderos o falsos, es necesario asumir de antemano como válido el concepto de rigidez y luego mostrar que otros predicados, que no son términos de clases naturales, resultarían rígidos también en lógica de segundo orden. Esto es lo que haremos.

Consideremos los siguientes pares de oraciones. Al lado derecho de la oración aparece su esquematización en lógica de segundo orden.

(4) $\mathrm{El}$ rojo es un color $=\mathrm{CR}$

(5) La soltería es un estatus conyugal = ES

(6) Benji y Rintintín son perros; por lo tanto tienen una propiedad en común $=\mathrm{Pa} \& \mathrm{~Pb} \Rightarrow(\exists \mathrm{X})(\mathrm{Xa} \& \mathrm{Xb})$

(7) Juan y Pedro son mexicanos; por lo tanto tienen una propiedad en común $=\mathrm{Mj} \& \mathrm{Mp} \Rightarrow(\exists \mathrm{X})(\mathrm{Xj} \& \mathrm{Xp})$

De ser correcta la tesis Kripke-Putnam, entonces en la oración (4) y en la oración (6), las constantes predicativas $R$ y $P$ designan rígidamente las propiedades de ser rojo y perro, respectivamente. El problema es que para efectos lógicos, no hay ninguna diferencia entre (4) y (5), por un lado, y 
entre (6) y (7), por otro. Estas oraciones tienen exactamente las mismas formas lógicas. Así que si "rojo" y "perro" son designadores rígidos, entonces también, por paridad de razonamiento, tendrían que serlo "soltería" y "mexicano". Sin embargo, "soltería" y "mexicano" son términos alusivos a categorías sociológicas o legales; estas palabras no designan nada físico o material. Por ende no está claro en qué sentido designarían rígidamente.

Lo mismo aplica para cualquier otro predicado no natural, incluso términos que denotan productos o artefactos humanos, tales como "lápiz", "bolígrafo", "silla", "marbete" y "computadora". El problema, en suma, es que la noción de rigidez se extendería a todos estos otros predicados también, y de este modo se trivializaría. Dejan de ser tan especiales los términos de clases naturales. ${ }^{6}$

Un corolario inmediato a este problema lógico es de carácter ontológico. Como hemos visto, estamos obligados lógicamente a admitir que predicados tales como "soltero", "lápiz" y "marbete" también resultarían rígidos. Cabe preguntarse entonces cuál sería la "esencia" denotada por dichos términos. ¿Acaso existe una esencia lapicera, una esencia marbética y una esencia compartida por todos los solteros? No está claro que tales esencias existan. De hecho, esta consecuencia inverosímil de la tesis Kripke-Putnam fue identificada hace tiempo por el filósofo Keith Donnellan, en un artículo suyo de 1983 (DONNELLAN, 1983). En este escrito Donnellan no se ocupa del aspecto lógico como tal, pero caracteriza como bizarra e inaceptable la consecuencia ontológica mencionada. 
A mi juicio dicho resultado ciertamente no favorece en nada la tesis Kripke-Putnam, pero quiero subrayar que la objeción hecha aquí es distinta y puramente lógica. El fallo de la referida tesis, desde la perspectiva de la lógica de segundo orden, es la extensión irrestricta (y por ende la trivialización) de la noción de rigidez a todo tipo de predicado.

También vale la pena recordar que podemos multiplicar ad infinitum ejemplos como los anteriores. Las formas lógicas que exhiben estos ejemplos, y muchas formas lógicas más, pueden interpretarse con los predicados que nos plazca, corroborando así el punto que queríamos establecer. Así pues, habiendo justificado de esta manera la primera premisa, el resto del argumento procede de inmediato. Debemos concluir entonces que la tesis Kripke-Putnam carece de sustancia filosófica, al interpretarse desde la perspectiva de la lógica de segundo orden.

Antes de finalizar, vale la pena aclarar que en lógica de segundo orden no surge el problema mencionado anteriormente sobre el alcance. Un enunciado singular de esta lógica, como el (4)-CR ("El rojo es un color")—en efecto puede moverse dentro o fuera de los cuantificadores de una oración más compleja que lo contenga, sin que esto altere las condiciones de verdad y el valor veritativo de la oración más grande. Esto es posible ya que el predicado "rojo" se ha convertido en un sujeto lógico representado por una constante predicativa, $R$. La constante predicativa en esta posición opera análogamente a una constante individual en lógica de primer orden. De modo que lo que era un problema para la tesis Kripke-Putnam desde la perspectiva de la lógica de primer orden ya no lo es desde el punto de vista de la 
lógica de segundo orden. La objeción desde dicha lógica es, reiteramos, la trivialización de la noción de rigidez.

\section{CONCLUSIÓN}

En conclusión, en este trabajo se ha argüido que la tesis Kripke-Putnam sobre los términos de clases naturales es ininteligible desde un punto de vista lógico. La semántica adscrita a dichos términos por la tesis Kripke-Putnam debe poder representarse ya sea en lógica de primer orden o en lógica de segundo orden, pero al implementar la tesis en dichos lenguajes el resultado es un dilema inaceptable para el defensor de la tesis: o bien los términos de clases naturales no son referenciales (y por ende no son rígidos), o bien sí son referenciales y rígidos, pero también resultan rígidos todos los demás predicados. Por consiguiente, la tesis KripkePutnam es o falsa o trivial desde la perspectiva de la lógica matemática clásica.

En este trabajo no se ha considerado la referida tesis desde la perspectiva de sistemas lógicos no clásicos, tales como la lógica modal. Y de hecho alguien quizás podría argumentar que es en lógica modal donde la tesis Kripke-Putnam tendría una clara aplicación y donde mejor se capturaría su sentido. Después de todo, la lógica modal es la lógica que trata expresamente sobre las nociones de posibilidad y necesidad, y en la cual se definen formalmente los conceptos de "rigidez" y "mundo posible". Presuntamente el verdadero hogar de la tesis Kripke-Putnam es la lógica modal. 
El problema con esta propuesta es que la lógica modal también es meramente una extensión de la lógica de primer orden, y por ende todo lo que vale para la lógica de primer orden también vale para la lógica modal. En otras palabras, lo que no tiene sentido en lógica de primer orden, tampoco tiene sentido en lógica modal. Como cuestión de hecho, no existe ningún sistema modal que contenga símbolos o reglas especiales para términos de clases naturales rígidos. En estos sistemas, sólo las constantes individuales son rígidas. Por ende no habría manera de articular la tesis Kripke-Putnam en esta lógica.

En mi opinión, el peso cumulativo de las críticas a la tesis Kripke-Putnam, desarrolladas a lo largo de los años y décadas, inclinan la balanza decisivamente en contra de la tesis. El presente trabajo se une a esta multitud de críticas, pero con la finalidad ulterior de esclarecer la dimensión lógica de esta provocadora y controversial tesis.

\section{NOTAS}

${ }^{1}$ Professor permanente na Universidade de Puerto Rico. Ph.D. City University of New York. E-mail: pdbaumann@gmail.com.

${ }^{2}$ En otros trabajos he ofrecido varias razones para rechazar la perspectiva general que subyace a la tesis Kripke-Putnam, y me he manifestado a favor de una concepción alterna; aquí sin embargo no tendremos espacio para repetir esos argumentos. (Véase, e.g., [BAUMANN, 2010] y [BAUMANN, 2013].) Tampoco hay espacio para repasar los argumentos a favor de la tesis Kripke-Putnam ofrecidos por estos dos filósofos; en todo caso se trata de argumentos harto conocidos. Sólo diré brevemente que dichos argumentos en el fondo apelan a nuestras intuiciones sobre varios escenarios imaginarios 
o experimentos mentales, un proceder metodológicamente cuestionable, como es bien sabido. La crítica elaborada a continuación no depende de intuición alguna; se basa únicamente en consideraciones lógicas formales. ${ }^{3}$ Véase (SOAMES, 2002) para una explicación exhaustiva acerca de la relación entre rigidez y estas otras propiedades semánticas, tanto en el caso de los nombres propios (Caps. 2 y 3 ) como para los términos de clases naturales (Caps. 9 y 10).

${ }^{4}$ Estrictamente, modus tollens se le aplicaría a las esquematizaciones usuales de las premisas, las cuales no se dan aquí por ser innecesarias.

${ }^{5}$ Normalmente diríamos que es el cuantificador universal $(\forall \mathrm{z})$, cuya variable ligada figura en la estructura de la función proposicional que simboliza la palabra "conejo", el que está dentro del alcance de los existenciales, porque la función proposicional que lleva a cabo la atribución de "ser conejo" no puede estar sola en el esquema. Pero estrictamente hablando no hay problema alguno en decir que la letra predicativa $C$ o la función proposicional $C z$ están en el alcance de todos los cuantificadores, puesto que en efecto vienen después de los cuantificadores en el orden de los símbolos que componen el esquema.

${ }^{6}$ Para estar claros, repetimos que el problema es que estos enunciados tendrían las mismas formas lógicas; el lenguaje lógico como tal no puede distinguir entre estos predicados-predicados que nosotros sabemos no son términos de clases naturales y a los cuales no les aplica la tesis KripkePutnam. 


\section{REFERENCIAS}

BAUMANN, P. Are proper names rigid designators? Axiomathes 20, 2010, pp. 333-46.

BAUMANN, P. Reevaluando la tesis Kripke-Putnam. Argumentos 9, 2013, pp. 270-94.

DONNELLAN, K. Kripke and Putnam on natural kind terms. En C. GINET y S. SHOEMAKER (eds.), Knowledge and Mind. Oxford: Oxford University Press, 1983, pp. 84-104.

KRIPKE, S. El nombrar y la necesidad. Ciudad de México, Universidad Autónoma de México, 1995. [Traducción al español de Margarita M. Valdés de Naming and Necessity. Cambridge, MA: Harvard University Press, 1980.]

PUTNAM, H. The meaning of "meaning". En Minnesota Studies in Philosophy of Science 7. Minneapolis: University of Minnesota Press, 1975, pp. 131-93.

PUTNAM, H. Significado y referencia. En L.M. Valdés Villanueva (ed.), La búsqueda del significado, Madrid, Editorial Tecnos, 2005, pp. 153-64. [Traducción al español de L.M. Valdés Villanueva de PUTNAM, H. "Meaning and reference", Journal of Philosophy Vol. 70, No. 19, New York, November 1973, pp. 699-711.]

SOAMES, S. Beyond Rigidity: The Unfinished Agenda of Naming and Necessity. Oxford: Oxford University Press, 2002.

ENVIADO EM: $15 / 01 / 2016$ APROVADO EM: 20/05/2016 